\title{
Personality Profile of Patients with Vocal Cord Nodules
}

\author{
(D) Ceki Paltura1 ${ }^{1}$ (1) Hakan Serdar Şengül2
}

1istanbul Gaziosmanpaşa Taksim Training and Research Hospital, Clinic of Otolaryngology Head and Neck Surgery Clinic, Istanbul, Turkey 2istanbul Gaziosmanpaşa Taksim Training and Research Hospital, Clinic of Clinical Psychology, İstanbul, Turkey

\section{Abstract}

Objective: We aimed to evaluate the susceptibility of patients with vocal cord nodules to psychoticism, extraversion, or neuroticism from the normal healthy population using the Eysenck's Personality inventory.

Methods: A study cohort consisting of patients followed up with vocal cord nodules and age- and gender-matched healthy controls was asked to answer the questions in the Eysenck's Personality inventory in a quiet and calm environment. The data were then evaluated and scored by the clinical psychologist, and personality profiles were determined.

Results: Eighty-six subjects (43 patients-43 controls) were included in the study. There was no significant difference between the groups in terms of mean scores of psychoticism ( $p=0.88)$ and extraversion $(p=0.376)$, whereas the mean scores of neuroticism $(p=0.027)$ and lie $(p<0.01)$ were significantly different.

Conclusion: Although it is frequently encountered in daily practice, the personality characteristics of patients with vocal cord nodules are easily missed. However, determining this condition and therapy in this area may positively affect the treatment of the disease and may help to establish appropriate behavioral patterns to prevent recurrence.

Keywords: Vocal cord nodules, Eysenck's Personality inventory, psychotism

\section{INTRODUCTION}

Vocal cord nodules are seen at the junction of the middle $1 / 3$ and the anterior $1 / 3$ of the vocal cords. They usually occur as a result of excessive vibratory vocal trauma on the vocal cords $(1,2)$. As a result of vibratory trauma, superficial lamina propria is disrupted and collagen 4 and fibronectin accumulate in this area (2). As a result of this accumulation, the vocal cords cannot be completely closed in the midline and laryngostroboscopy shows a typical hourglass view. Vocal cord nodules are seen in 0.5 to $1.3 \%$ of the general population (3). This disease is more common in people who use their voice for work, such as singers or teachers. It has been shown that most of the cases with vocal cord nodules tend to overuse their voices due to personality characteristics (4). Differences or tendencies in individuals' responses, such as thoughts, behaviors and emotions, which cannot be explained according to their situation, time or environment, can be defined as personality profile (5). Therefore, personality includes subjective and fixed features of the individual. Most of the authors think that because of these features, personality includes all aspects of the person from gestures and walks to speech and thinking (6). Many personality theorists have conceptualized personality in different ways. In the definition of personality, Eysenk used introversion and extroversion (E) dimension as the basis. He has created a three-dimensional structure by adding psychoticism $(\mathrm{P})$ to the personality, which he had previously thought of as neuroticism $(\mathrm{N})$ and $\mathrm{E}$. E dimension shows social behaviors and impulsivity, $\mathrm{N}$ dimension shows emotional and overreactive behaviors, and $P$ dimension shows distancing from people (7). In some previous studies, it has been found that features such as impulsivity and hyperactivity are more common in people with voice nodules $(1,8,9)$. At the same time, it is noteworthy that patients with vocal cord nodules exhibit $E$ characteristics and make statements about this. In this study, we aimed to evaluate the susceptibility to $\mathrm{P}, \mathrm{E}$, or $\mathrm{N}$ of patients with vocal cord nodules by Eysenck's Personality inventory (EPQ) and to evaluate the difference from normal healthy population. 


\section{METHODS}

The study was started with the approval of the ethics committee of İstanbul Gaziosmanpașa Taksim Training and Research hospital (78/2018). The patients who were followed up with vocal cord nodule in the otorhinolaryngology clinic of our hospital and who were older than 18 years were asked to answer EPQ that consists of 101 questions in a quiet and calm environment. The control group included age- and gender-matched patients with no disease in the vocal cords. The data were then evaluated and scored by a clinical psychologist and personality profiles were determined.

\section{Statistical Analysis}

Normality of data was assessed using Shapiro-Wilk test, histogram, Q-Q plot and box plot graphs. Independent t-test was used to compare patient and control groups, as the data showed normal distribution. The level of significance was taken as $p<0.05$ with a two-tailed test. Analysis was performed using NCSS 10 (Kaysville, Utah, USA).

\section{RESULTS}

Forty-three patients and 43 age and gender-matched healthy subjects were included in the study. In each group, there were 37 female and six male subjects. The mean age of the patient group was $31.67 \pm 10.38$ years and $31.88 \pm 10.2$ years in the control group. The mean $\mathrm{P}$ score was $3.58 \pm 1.82$ in the patient group and $4.27 \pm 1.91$ in the control group. The mean score of $E$ was $13.30 \pm 3.96$ in the patient group and $12.51 \pm 4.27$ in the control

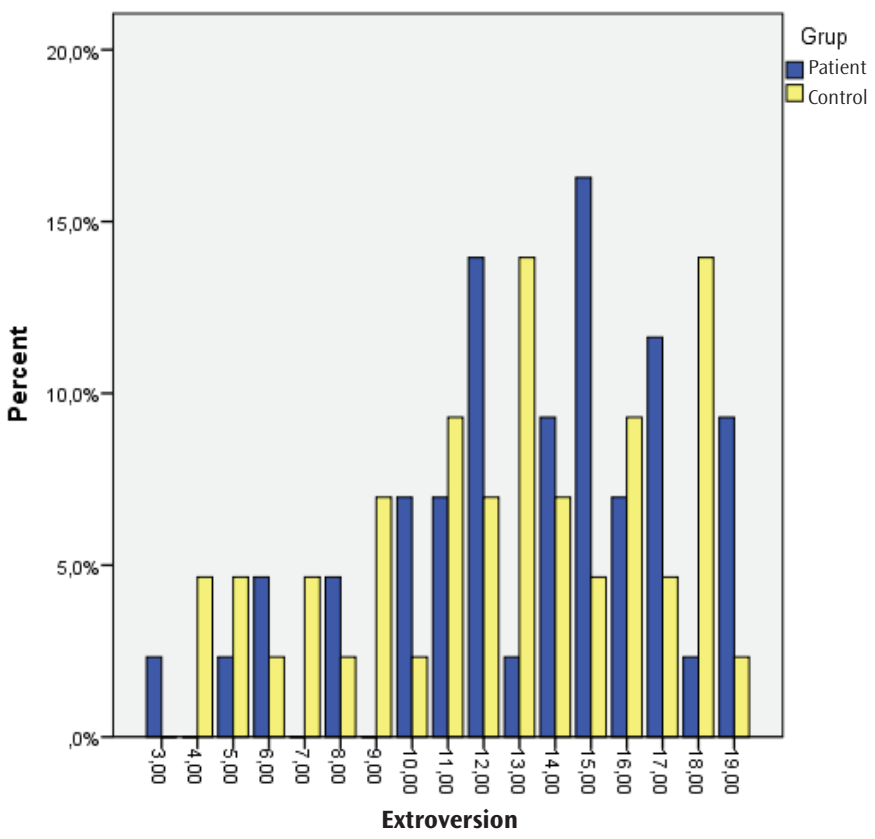

Figure 1. Extroversion scores of the patient and control groups group (Figure 1). The mean score of $\mathrm{N}$ was $15.11 \pm 4.04$ in the patient group and $13.04 \pm 4.49$ in the control group. This result was found to be statistically different $(p=0.027)$ (Figure 2). Lie subscale scores were scored as $15.23 \pm 2.61$ in the patient group and $12.81 \pm 3.34$ in the control group. The total score of the lie subscale was significantly higher in the patient group compared to the control group $(p<0.001)$ (Table 1).

\section{DISCUSSION}

Vocal cord nodules, cysts and polyps, which are called benign vocal cord lesions, usually occur as a result of one or more repeated phonotrauma $(2,10)$. In recent years, psychogenic factors and stress have been implicated in the development

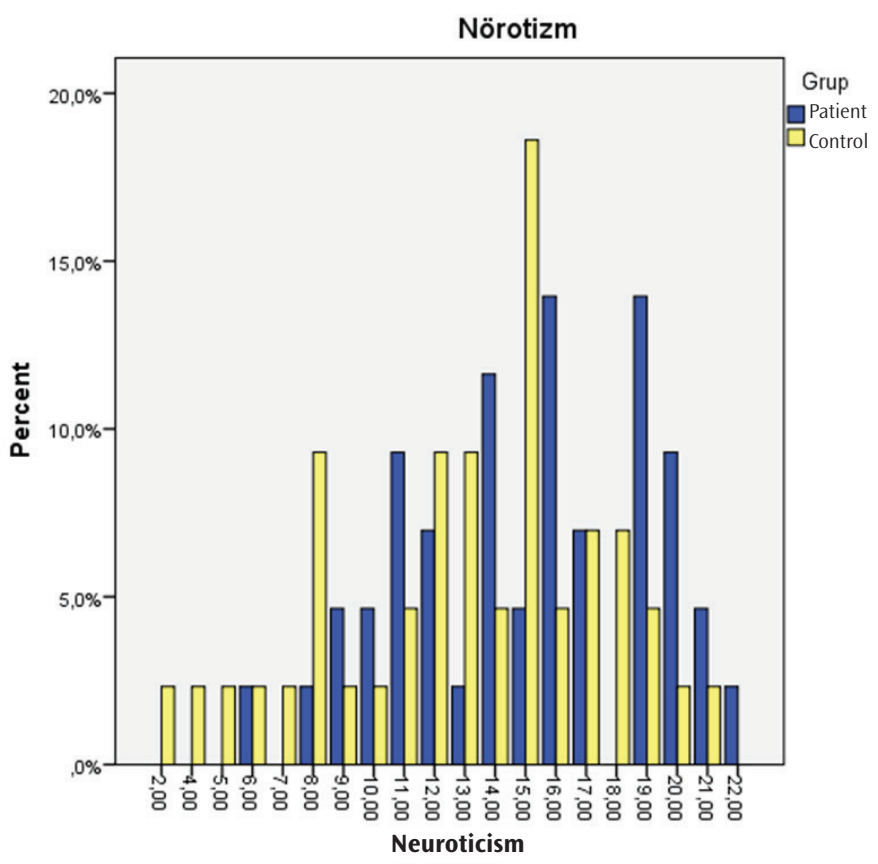

Figure 2. Neuroticism scores of the patient and control groups

Table 1. Distribution of the scores obtained in the inventory by groups and statistical results

\begin{tabular}{|l|l|l|l|l|l|}
\hline \multicolumn{7}{|c|}{ Statistics } \\
\hline \multirow{2}{*}{ Psychoticism } & Group & $\mathbf{n}$ & Mean & $\begin{array}{l}\text { Standard } \\
\text { deviation }\end{array}$ & $\mathbf{p}$ \\
& Patient & 43 & 3.5814 & 1.82877 & 0.88 \\
\cline { 2 - 7 } & Control & 43 & 4.2791 & 1.91890 & \\
\hline \multirow{2}{*}{ Extroversion } & Patient & 43 & 13.3023 & 3.96734 & 0.376 \\
\cline { 2 - 7 } & Control & 43 & 12.5116 & 4.27268 & \\
\hline \multirow{2}{*}{ Leuroticism } & Patient & 43 & 15.1163 & 4.04268 & 0.027 \\
\cline { 2 - 7 } & Control & 43 & 13.0465 & 4.49313 & \\
\hline & Patient & 43 & 15.2326 & 2.61713 & $<0.01$ \\
\cline { 2 - 6 } & Control & 43 & 12.8140 & 3.34704 & \\
\hline
\end{tabular}


of benign vocal cord lesions like many other diseases. It has been reported in some studies that stress affects sound quality (11) and causes acoustic changes (12-14). Smith and Seidel (15) reported that stress might cause voice problems (voice unsteady, strained, tense, loud, quiet) that would prevent communication in patients. In this study, the responses of the patients with vocal cord nodules to the EPQ were examined and the personality profile of the patients was investigated. The results were also compared with the normal population and their differences were evaluated. EPQ is one of the inventories that are frequently used in the outpatient clinic to evaluate introversion and $\mathrm{E}$ of individuals, and considered to be reliable due to its consistent results. The inventory was developed primarily to assess the normal characteristics of the individual, rather than the diseased conditions (10). According to H.J. Eysenck and S.B.G. Eysenck, the personality of the individual can be evaluated as a threedimensional structure. These three dimensions are P, $\mathrm{N}$ and $\mathrm{E}$. In order to evaluate the personality of the individual, they have worked on many inventories, and EPQ took its final form. EPQ is an inventory of 101 questions, 90 original and 11 substitute, for the purpose of evaluating four personality characteristics: P, E, N and lie. Twenty-three of these questions can be used to evaluate N, 21 for E, 25 for P, and 21 for lie. The individual is asked to answer "yes" and "no" to each question while completing this questionnaire (10). In this study, the $\mathrm{N}$ and lie values of our patients were higher than the control group and this difference was found to be statistically significant. According to these results, it can be said that the patient group is more anxious and more susceptible to stress than the control group. Moreover, the high lie score of the patient group may indicate that they do not feel socially sufficient and need to show themselves better. In a similar study, Barakah et al. (16) found that psychogenic factors were associated with benign vocal cord lesions, particularly in the formation of nodules, polyps, and cysts. Although the personality characteristics of patients with vocal cord nodules are observed in daily practice, not enough studies have been conducted. The effects of psychological characteristics on otolaryngology are the areas that have been studied more recently. In a limited number of previous studies, it was shown that personality characteristics were related to vocal cord nodule formation. In our study, we also found that $\mathrm{E}$ and $\mathrm{N}$ were more prominent in patients with vocal cord nodules.

\section{Study Limitations}

The limited number of patients and the fact that the psychiatric features of the patients such as depression and anxiety were not excluded are the limitations of our study.

\section{CONCLUSION}

In our study, it was found that individuals with vocal cord nodules had more neurotic features than the control group. Although this shows that patients cannot use the right defense mechanisms to cope with stress, it can be accepted that somatic symptoms are common in the patient group. Although it is common in daily practice, the personality characteristics of patients with vocal cord nodules are easily missed. However, determining this condition and therapy in this area may positively affect the treatment of the disease and may help to establish appropriate behavioral patterns to prevent recurrence.

\section{Ethics}

Ethics Committee: The study was reviewed by the ethics committee of İstanbul Gaziosmanpaşa Taksim Training and Research Hospital and it was found that there was no ethical problem in its publication (78/2018).

Informed Consent: Obtained from all patients.

Peer-review: External and internal peer-reviewed.

\section{Authorship Contributions}

Surgical and Medical Practices: C.P., Concept: C.P., Design: C.P., H.S.S., Data Collection or Processing: C.P., Analysis or Interpretation: H.S.S., Literature Search: C.P., H.S.S., Writing: C.P., H.S.S.

Conflict of Interest: No conflict of interest was declared by the authors.

Financial Disclosure: The authors declared that this study received no financial support.

\section{REFERENCES}

1. El Uali Abeida M, Fernández Liesa R, Vallés Varela H, García Campayo J, Rueda Gormedino P, Ortiz García A. Study of the influence of psychological factors in the etiology of vocal nodules in women. J Voice 2013;27:129.e15.

2. Dikkers FG, Nikkels PG. Benign lesions of the vocal folds: histopathology and phonotrauma. Ann Otol Rhinol Laryngol 1995;104:698-703.

3. Nagata K, Kurita S, Yasumoto S, Maeda T, Kawasaki H, Hirano M. Vocal fold polyps and nodules. A 10-year review of 1,156 patients. Auris Nasus Larynx $1983 ; 10: 27-35$

4. Bastian RW, Thomas JP. Do talkativeness and vocal loudness correlate with laryngeal pathology? A study of the vocal overdoer/underdoer continuum. J Voice 2016;30:557-62

5. Linda V. Berens. Sixteen personality types: Descriptions for self-discovery. Telos Publications, California, 1999.

6. Taymur I, Türkçapar M.H. Kișilik: Tanımı, sınıflaması ve değerlendirmesi psikiyatride güncel yaklaşımlar-current approaches in psychiatry 2012;4:15477. 
7. Eysenck HJ, Eysenck SBG. Manual of the eysenck personality questionnaire (adult and junior). London, Hodder \& Stoughton, 1975. Personality: Description, Classification and Evaluation

8. Yano J, Ichimura K, Hoshino T, Nozue M. Personality factors in pathogenesis of polyps and nodules of vocal cords. Auris Nasus Larynx 1982;9:105-10.

9. Ratajczak J, Grzywacz K, Wojdas A, Rapiejko P, Jurkiewicz D. Role of psychological factors in pathogenesis of disturbances of voice caused with vocal nodules. Otolaryngol Pol 2008;62:758-63.

10. Eysenck SBG. The validity of a personality questionnaire as determined by the method of nominated groups. Life Sciences 1962;1:13-8.

11. Mossallam I, Kotby MN, Ghaly AF, Nassar AM, Barakah MA. Histopathological aspects of benign vocal fold lesions associated with dysphonia. In: Vocal Fold Histopathology San Diego: College-Hill Press 1986;65-80.
12. Everly GS, Lating JM. A Clinical guide to the treatment of human stress response. 2nd ed. New York, NY: Kluwer Academic Publischers; 2002.

13. Mendoza E, Caballo G. Acoustic analysis of induced vocal stress by means of cognitive workload tasks. J Voice 1998;12:263-73.

14. Mendoza E, Caballo G. Vocal tremor and psychological stress. J Voice 1999;13:105-12.

15. Smith JC, Seidel JM. The factor structure of self-reported physical stress reactions. Biofeedback Self-Regulation 1982;7:35-47.

16. Barakah MA, Mohammed MM, Shab YAA, Hegazi MA, Shoeib RM, Quriba AS. Psychogenic background of minimal associated pathological lesions of the vocal folds. Egyptian Journal of Ear, Nose, Throat and Allied Sciences 2012;13:55-9. 